\title{
The Geochemical Speciation of Hand-dug Well Water of Kakamega County, Kenya
}

\author{
Joshua Kiprotich Kibet ${ }^{1,}$, , David Munyonge Kituyi ${ }^{1}$, Samuel Limo Chelimo ${ }^{2}$, \\ Lorna Chemutai Chesir ${ }^{1}$ \\ ${ }^{1}$ Department of Chemistry, Egerton University, Egerton, Kenya \\ ${ }^{2}$ Department of Physics, University of Eldoret, Eldoret, Kenya
}

Email address:

jkibet@egerton.ac.ke (J. K. Kibet), dkituyi@gmail.com (D. M. Kituyi), limolimoraloon@gmail.com (S. L. Chelimo), loche.lc@gmail.com (L. C. Chesir)

${ }^{*}$ Corresponding author

\section{To cite this article:}

Joshua Kiprotich Kibet, David Munyonge Kituyi, Samuel Limo Chelimo, Lorna Chemutai Chesir. The Geochemical Speciation of Hand-dug Well Water of Kakamega County, Kenya. American Journal of Applied Chemistry. Vol. 4, No. 2, 2016, pp. 40-49.

doi: 10.11648/j.ajac.20160402.12

Received: February 7, 2016; Accepted: February 18, 2016; Published: March 19, 2016

\begin{abstract}
This contribution makes use of AquaChem computational platform to determine the mineral assemblage and mineral speciation of hand-dug well water of Kakamega Metropolis. Mineral speciation, hydrochemical behavior, charge balance error (CBE), and piper plots are important factors in establishing mineral composition and water histories of a given hydrological regime. The ionic strength as predicted using AquaChem was between 0.0051 and 0.0068 in the hand-dug wells investigated in this study. AquaChem gave a charge balance error (CBE) of between 38.0 and - 0.9, and predicted that Kakamega waters belong to the class of primary waters having very low concentration of total dissolved solids (TDS $<150$ $\mathrm{mg} / \mathrm{kg}$ ). Piper plots indicated that the water is possibly from local supply of each element throughout history, origin, and migration of the water. Evidently, the oxygen-rich ions represented by $\mathrm{HCO}_{3}^{-}$and $\mathrm{SO}_{4}^{2-}$ were abundant compared to $\mathrm{Cl}^{-}$and $\mathrm{F}^{-}$. This implies that the water originates from shallow aquifers, and is of low salinity.
\end{abstract}

Keywords: AquaChem, Aquifer, Charge Balance Error, Speciation

\section{Introduction}

Ground water resource management, represents the interface between human and hydrological systems, and has a direct impact on human geography and socio-economic development [1]. Mineral speciation is important in predicting the interaction of different chemical forms in a water system. In this study we present the first groundwater study in Western Kenya (Kakamega Metropolis) using AquaChem computer platform in order to predict mineral speciation in hand-dug well water, its origin, as well as well water histories. Ground water is a key resource for various activities including vegetation, agriculture and human consumption in many rural settings of the world [1]. The ability to understand the mineral assemblage in groundwater is important in monitoring the hydrological behavior and saturation indices of significant solubility controlling minerals in water systems $[2,3]$. Based on identification of potential minerals, the results from the $\mathrm{pH}$ dependence test is a finger print in chemical speciation [3]. The calculation of $\mathrm{pH}$ and multi-component chemical equilibria in water-rock reactions is critical in establishing mineral assemblage and buffers that control hydrological systems.

\subsection{AquaChem Computational Suite}

AquaChem is a software package developed specifically for graphical and numerical analysis and modeling of water quality data $[2,4]$. It presents a full customizable database of physical and chemical parameters and offers a comprehensive choice of analysis tools, calculations, and graphs for interpreting water quality data [4]. AquaChem's data analysis capabilities cover a wide range of functionalities and computations including unit conversions, charge balance, sample comparison and mixing, statistical 
summaries, and trend analyses. These powerful analytical capabilities are complemented by a comprehensive selection of commonly used plotting techniques to represent the chemical characteristics of water quality data $[4,5]$. AquaChem provides a comprehensive choice of 23 different plotting techniques typically used for aqueous geochemical data analyses and interpretation [5].

\subsection{The Study Area}

Kakamega Metropolis is located in the western part of Kenya between $02.833^{\circ} \mathrm{N}$ and $34.7500^{\circ} \mathrm{E}$, and covers an area of $\sim 5 \mathrm{Km}^{2}$ (Fig. 1). The major economic activity in the area is gold mining in small scale, sugar cane farming, and fishing. The source of drinking water is largely hand-dug wells suspected to contain a range of micro-ionic species.
Evidently, the quality of water may be affected by rock weathering and waste materials from mining sites that may result in the release of toxic chemicals into both the environment and the aquatic system $[3,6]$. The problems caused by mining activities include rapid loss of farm lands, loss of water sheds, heaping of rocks and mine waste around trees, and silting of rivers and streams. All these activities have the ability to affect the water quality of ground water.

Accordingly, this study will provide policy makers and land owners in western Kenya and the Lake Victoria water basin with knowledge of detailed mineral speciation of the hand-dug well water in Kakamega Metropolis and also serve as a guide for hydrochemistry evaluation of other mining areas in Kenya that share similar geochemical history.

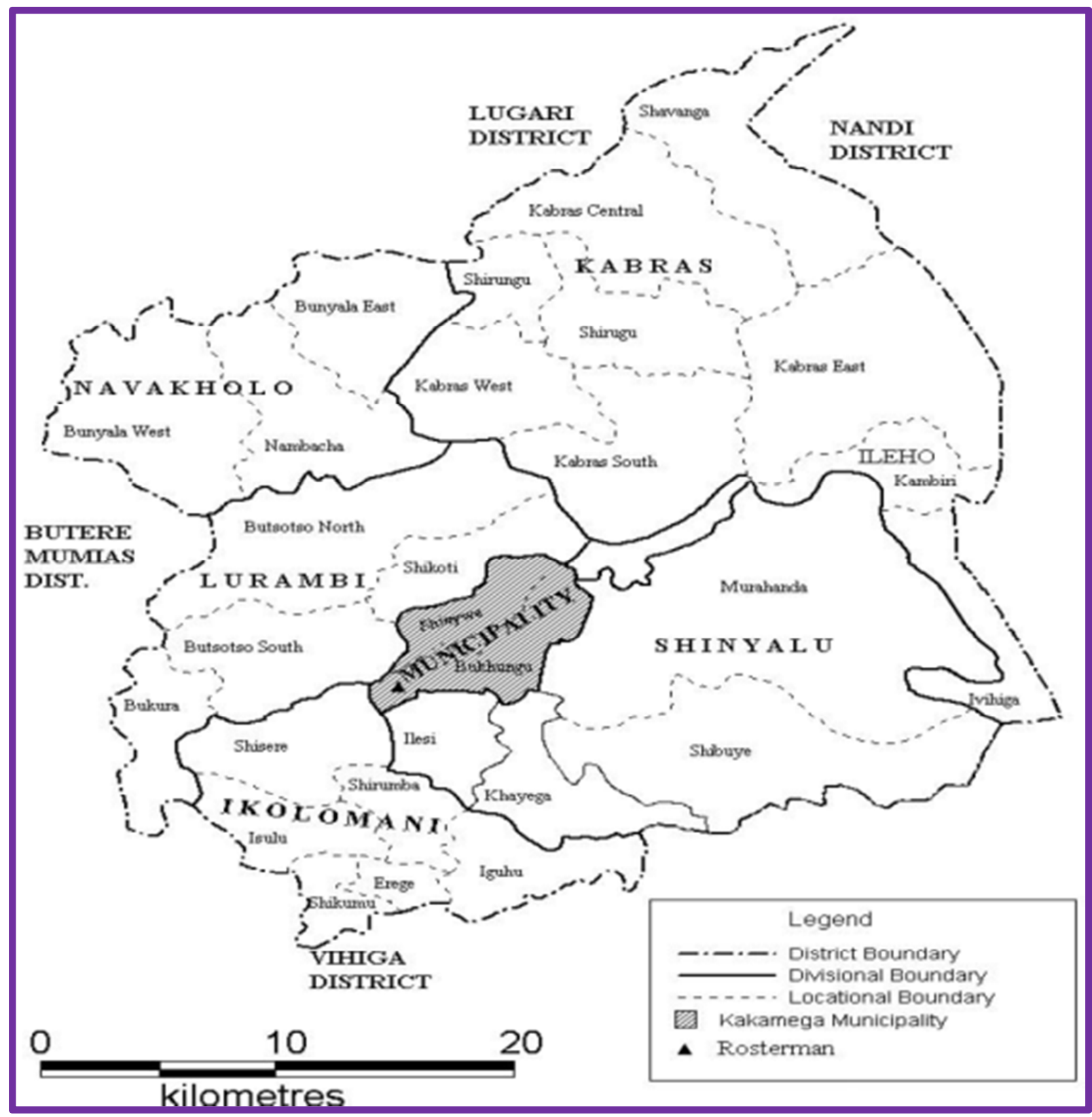

Fig. 1. A map of Kakmega District showing the research area (Kakamega Municipality). 


\section{Experimental Protocol}

\subsection{Materials}

All the chemicals used in this study were of analytical grade unless otherwise stated. The reagents and analytical procedure utilized in this study is detailed in reference [7].

\subsection{Titrimetric Analysis and pH Measurements}

The concentration of essential elements including $\mathrm{Mg}, \mathrm{K}$, $\mathrm{Na}$, sulphates, total carbonate, $\mathrm{F}$ and $\mathrm{Cl}$ in hand dug well water were determined automatically by means of a titroline processor using appropriate reagents. The detailed procedure for analysis of these components is described elsewhere [7]. The $\mathrm{pH}$ of the water samples was determined using a $\mathrm{pH}$ meter. The $\mathrm{PH}$ probe was rinsed thoroughly using deionized water and calibrated using buffers of $\mathrm{pH} 7$ and $\mathrm{pH}$ 9. Since $\mathrm{pH}$ values are temperature dependent, the measurements were carried out at the temperature of the well water. Temperature measurements were taken as soon the water was sampled in order to investigate if there was any thermal input in the well water. The electrical conductivity of the water samples were measured using a conductivity meter under standard conditions of temperature and pressure. Measurement of conductivity was made immediately at the sample collection site because conductivity changes with time.

\subsection{Quality Control (QC)}

Control sample (bottled water) was analyzed for essential elements, sulphates, carbonates, fluorides, and chlorides prior to the analysis of water sample from hand-dug wells. Standard concentrations were prepared in such a way that it was within the bracket of components in the water sample. This is termed the analysis range. The analyses of samples were conducted in replicates to enhance the validity and reproducibility of the results. To one sample out of 12 samples, a known concentration of the analyte was added and the recovery checked. A recovery of $\sim 95 \%$ was obtained and this was considered good enough.

\subsection{Computational Analysis Using AquaChem}

AquaChem is a computational package developed specifically forgraphical and numerical analysis and modeling of water quality data [4]. There is also an onscreen instant display of analytical ion balance and ionic strength, as data is entered and sample may be completely balanced (charge neutralized as speciated) by adjusting $\mathrm{Cl}^{-}$or some other species using the speciated ion balance results of an output run. AquaAhem can calculate the saturation indices for about 300 minerals [8]. The output from the AquaChem computer suite includes ionic strength and ion balance, activity coefficients, speciation in $\mathrm{meq} / \mathrm{L}$, and mineral solubility indices $[4,5]$.

\section{Results and Discussion}

The major essential elements and some physisological parameters including $\mathrm{pH}$ and total carbonate (TC) and total dissolved solids (TDS) are reported in table 1. Clearly, the oxygeneous components such as sulphates and total dissolved carbonate were found to overwhelm nonoxygenated species including $\mathrm{F}^{-}$, and $\mathrm{Cl}^{-}$.

Table 1. Major constituents and some physiological properties of hand-dug wells in Kakamega.

\begin{tabular}{|c|c|c|c|c|c|c|c|}
\hline Parameter $(\mathrm{mg} / \mathrm{L})$ & Sample 1 & Sample 2 & Sample 3 & Sample 4 & Sample 5 & Sample 6 & Sample 7 \\
\hline $\mathrm{Cl}^{-}$ & 0.34 & 0.3 & 0.42 & 0.3 & 0.46 & 0.36 & 0.24 \\
\hline $\mathrm{F}^{-}$ & 0.6 & 0.40 & 0.67 & 0.40 & 0.20 & 0.60 & 0.40 \\
\hline $\mathrm{SO}_{4}^{2-}$ & 6.3 & 1.00 & 1.11 & 2.41 & 3.93 & 0.15 & 0.07 \\
\hline $\mathrm{K}^{+}$ & 2.53 & 1.46 & 3.99 & 7.29 & 8.36 & 3.60 & 4.08 \\
\hline $\mathrm{Na}^{+}$ & 9.26 & 5.99 & 5.61 & 5.05 & 9.07 & 6.83 & 6.74 \\
\hline $\mathrm{Ca}^{2+}$ & 50.6 & 17.54 & 26.55 & 23.05 & 22.04 & 22.55 & 14.53 \\
\hline $\mathrm{Mg}^{2+}$ & 27.97 & 29.78 & 30.4 & 29.18 & 32.83 & 27.66 & 28.58 \\
\hline $\mathrm{TC}$ & 166.08 & 126.14 & 121.14 & 170.29 & 153.68 & 182.9 & 155.57 \\
\hline $\mathrm{pH}$ & 7.71 & 7.36 & 6.83 & 7.14 & 7.51 & 7.75 & 7.78 \\
\hline TDS & 142.31 & 39.65 & 78.66 & 70.43 & 130.25 & 125.58 & 42.56 \\
\hline
\end{tabular}

Legend: Sample 1- Lusui, Sample 2- Iguhu, Sample 3- Ikolomani 1, Sample 4- Ikolomani 2, Sample 5- Mupenji, Sample 6- Shilalunga, Sample 7- Shivikhwa

\subsection{The AquaChem Computational Out Put}

Evaluation of the hydrochemicalfacies in the water is extremely useful in gaining insight on the complex hydrochemical processes sub-surface. Water samples, S1 to S7 (Lusui, Iguhu, Ikolomani1, Ikolomani 2, Mupenji, Shilalunga, and Shivikhwa respectively), have been utilized to investigate the hydrochemical processes that control the water composition in the study area (Kakamega County).

\subsection{Ionic Speciation, Charge Balance Error and Ionic Strength}

Prior to the interpretation of geochemical data, it is instructive to carry out an initial check of the quality of the data. This was done based on the Charge Balance Error (CBE) by means of equation 1 


$$
\% \text { dev }=\frac{\Sigma_{\text {cations }}-\Sigma_{\text {anions }}}{\sum_{\text {cations }}+\Sigma_{\text {anions }}} \cdot 100
$$

which is based on the electroneutrality condition, where $\Sigma_{\text {cations }}$ and $\Sigma_{\text {anions }}$ represent the sum of the concentrations of major cations and major anions, respectively, all expressed in milliequivalent units. The summation of all cations and ionic strenght used to determine the charge balance error is presented in table 2. It is apparent from most samples that mass balance of ionic species was not achieved. While most charge balance error from various bore-hole waters was reasonable, that of sample 3 (Ikolomani 1) was way off,
$61.8 \%$. This may suggest different mineral buffers could be controlling the water of this bore-hole. These include haematite and magnetite which were not given prefferential treatment in this study. Therefore, future studies should focus on the ionic contributions of these important species. Despite these obvious descrepancies, the data provided in this study are of high quality. In any case, there is always some error in the measurement of cation and anion concentration. More importantly, this is one of the very first research studies to interface computational methods and experimental techniques in domestic water analysis in Kenya.

Table 2. Charge balance error and ionic strength of various water samples.

\begin{tabular}{lllll}
\hline Sample & Ecations (mol.eq.) & Sanions (mol.eq.) & CBE (\%) & Ionic Strength \\
\hline 1 & 0.0053 & 0.0036 & 38.5 & 0.0068 \\
2 & 0.0036 & 0.0029 & 23.8 & 0.0048 \\
3 & 0.0042 & 0.0022 & 24.9 & 0.0051 \\
4 & 0.0040 & 0.0031 & 38.0 & 0.0052 \\
5 & 0.0044 & 0.0030 & -0.9 & 0.0056 \\
6 & 0.0038 & 0.0038 & 11.0 & 0.0054 \\
7 & 0.0035 & 0.0031 & 0.0048 \\
\hline
\end{tabular}

Legend: Sample 1- Lusui, Sample 2- Iguhu, Sample 3-Ikolomani 1, Sample 4- Ikolomani 2, Sample 5- Mupenji, Sample 6- Shilalunga, Sample 7- Shivikhwa

A CBE of the order of magnitude of between $5 \%$ and $~ 12 \%$ is invariably regarded satisfactory [9]. Most of the samples utilized in this work unfortunately have $|\% \operatorname{dev}|>12 \%$, which is outside the acceptable threshold, except samples for S6 and S7 as seen in the graphs in Fig. 2, vide infra.
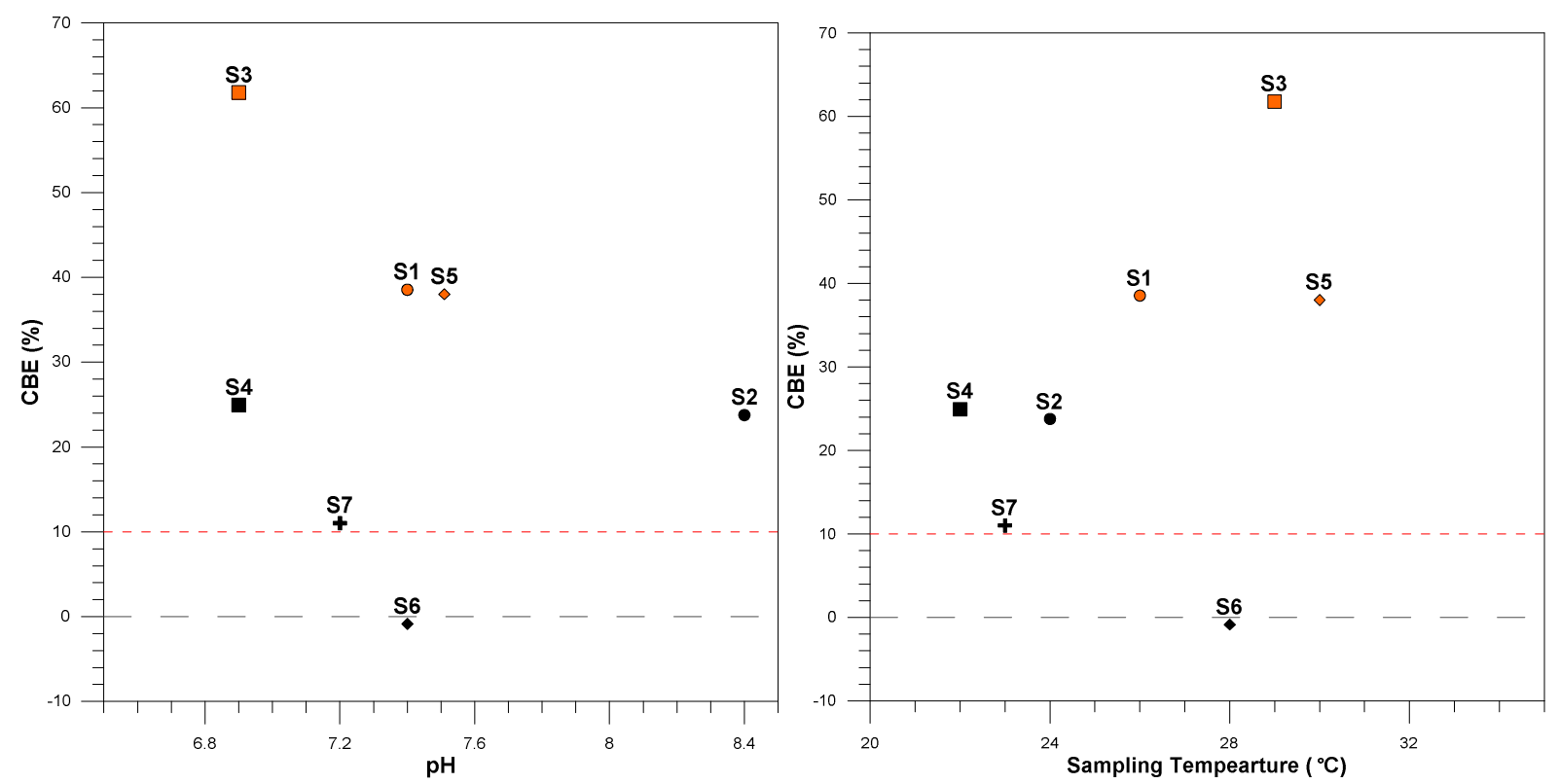

Fig. 2. CBE (\%) in relation to sampling temperature (left) and $p H$ (right).

Graphical methods in AquaChem computational code are useful in pointing out features of analyses and arrays of data which need to be studied closely. It has been observed previously that the principles of graphical interpretation are based on relationships of ions or ion pairs that form a chemical type of water [3]. However, it was previously noted that a single graph will not give all the information such as concentration of ions, classification of water types, identification of mixed waters of different compositions, characterization of some of the chemical processes that may take place in ground water circulation or the relationship of chemical composition to rock type $[4,10]$. In the triangular diagrams of major anions (Fig. 3, left), all samples from the investigated area are situated in the $\mathrm{HCO}_{3}$ field and, therefore, are bicarbonate-rich waters, while in the major cations (Figure 3 , right), all the samples from the study area are found in the $\mathrm{Ca}(+\mathrm{Mg})$ apex of the diagram and, therefore, are $\mathrm{Ca}-\mathrm{Mg}$-rich waters. This interpretation is based on the work of [10]. 

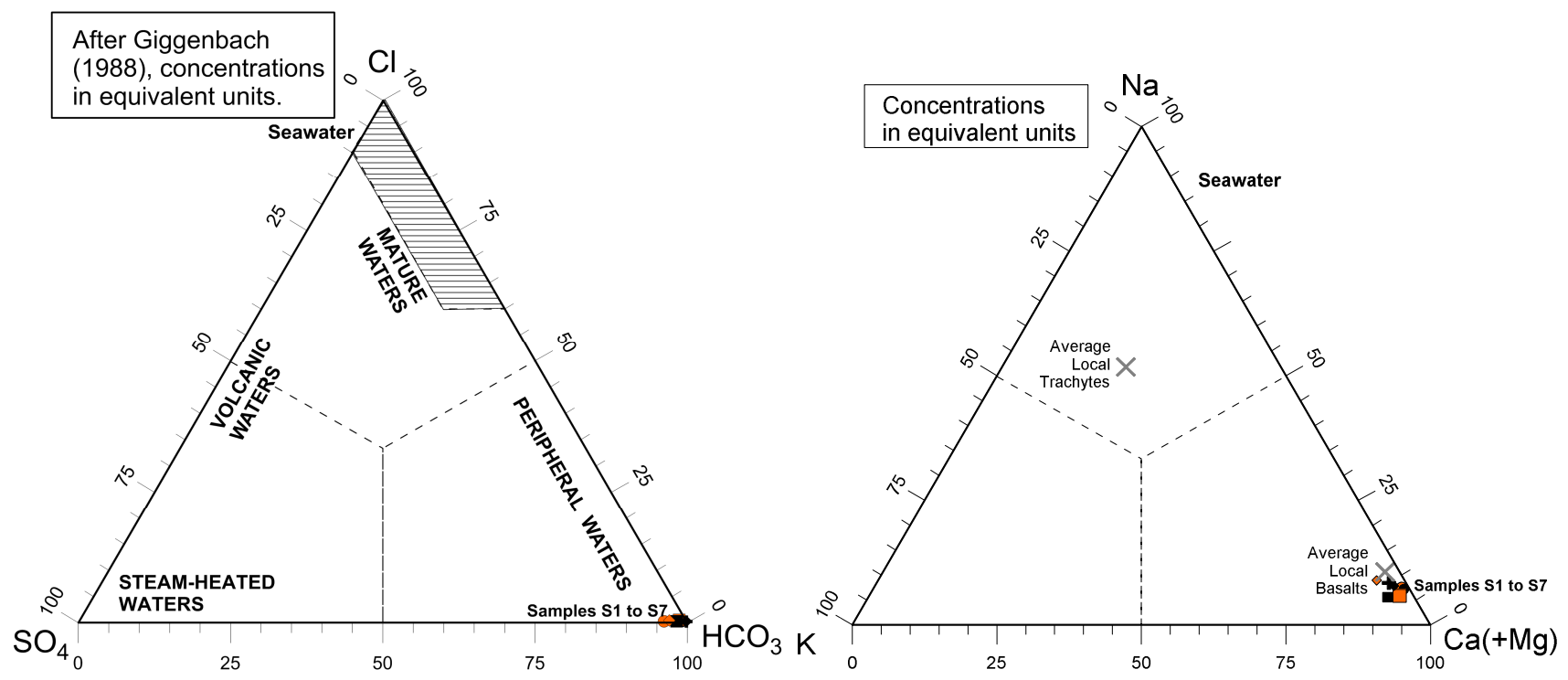

Fig. 3. Triangular diagrams of major cations and anions for the water samples from the study area.

It is evident from Fig. 3 that the water of Kakmega handdug wells falls in the peripheral water category which contains high levels of calcium and magnesium. Additionally, the mineral assemblage originates from average local basalts and has significant bearing on the mineral speciation of Kakamega metropolis.

\subsection{Correlation Plots}

Correlation plots are valuable for comparing chemical analyses in order to find differences or similarities in water

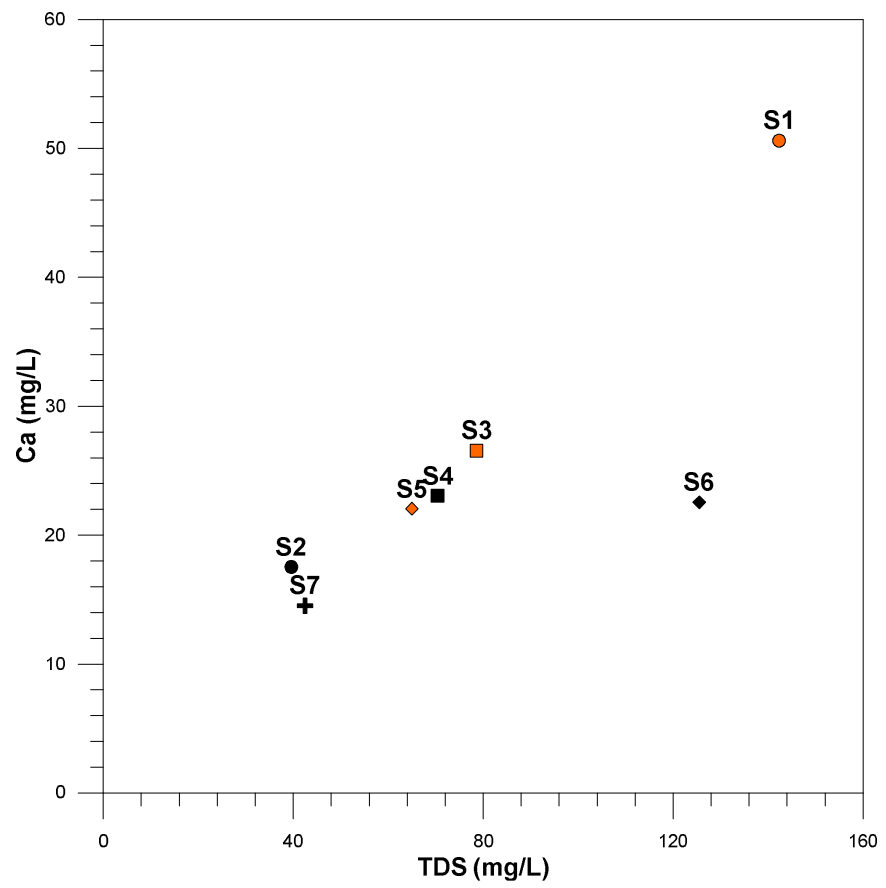

composition. The expression of relationship among ions or of one constituent to the total concentration in terms of mathematical ratios is one of the best techniques for showing correlation among types of waters. The results from Kakamega study area indicate that the $\mathrm{Ca}$ content in the water seems to correlate well with the dissolved content except for sample S6 but there appears to be no correlation between $\mathrm{Ca}$ and $\mathrm{Mg}$ (cf. Fig. 4). Ideally, the ratio of $\mathrm{Ca}$ and $\mathrm{Mg}$ is useful in studying water from carbonate based rocks.

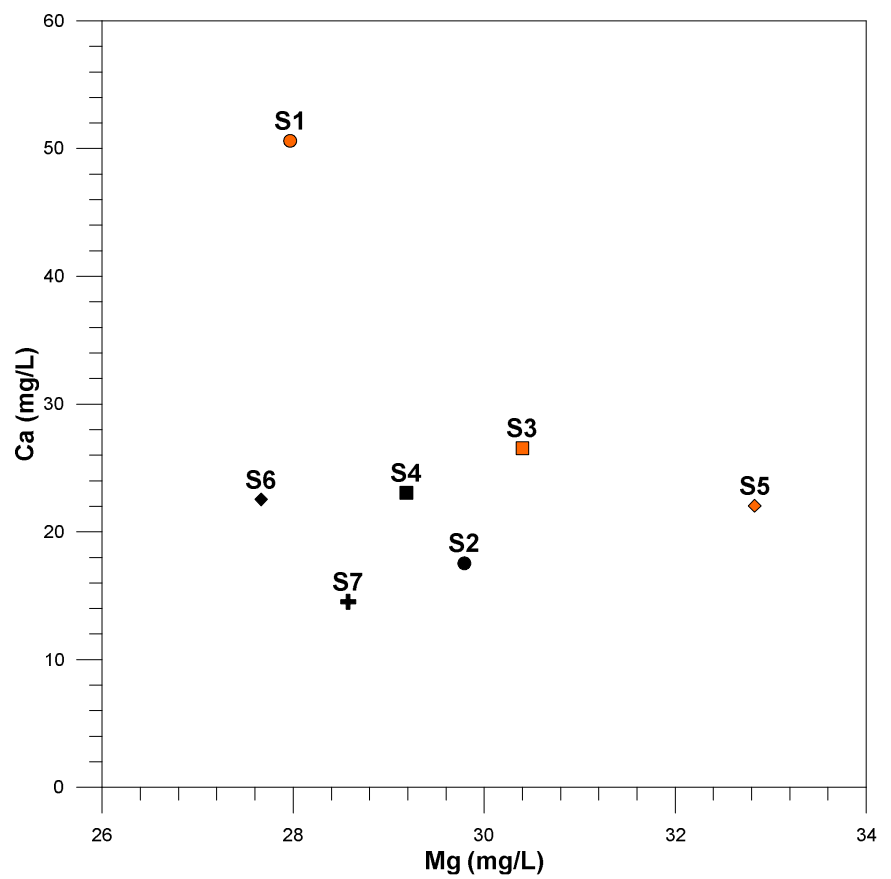

Fig. 4. Correlation plots for Ca and other Physico-chemical parameters (TDS and Mg).

Natural water commonly contains chloride, which is considered a mobile (conservative) constituent of reference. In this regard, water chemistry is frequently characterized by the relationship between chloride and other common ions such as 
$\mathrm{Mg}, \mathrm{Ca}, \mathrm{Na}, \mathrm{K}$, and sulphate. Fig. 5 reports the relationship between chloride in solution with TDS and $\mathrm{HCO}_{3}$.

These provide an understanding of the behavior of different solute species as well as detecting active processes controlling their concentrations in the waters [3]. It is therefore beneficial to examine a series of correlation plots in which the common solutes are correlated against chloride in

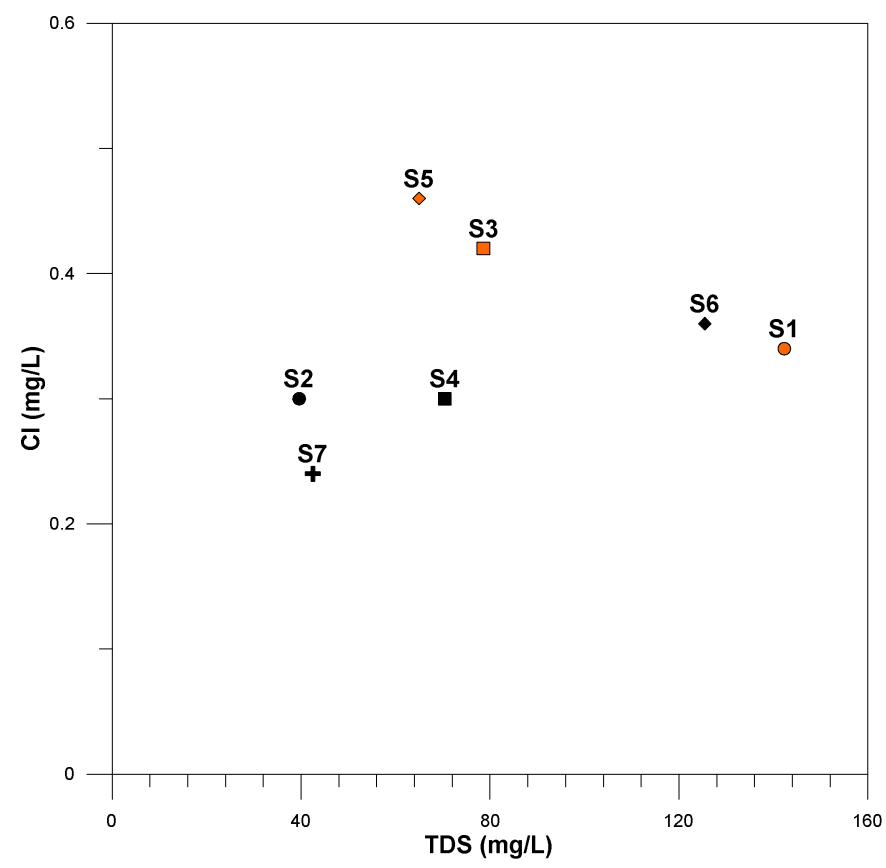

the area under study. From the results, there seems to be a relatively good correlation between chloride and the other chemical constituents for most of the samples, except for total dissolved solids (TDS), bicarbonate contents, sodium and potassium which show significant deviations. Fig. 6 presents a detailed relationship between chloride and other species of significant importance in mineral speciation.

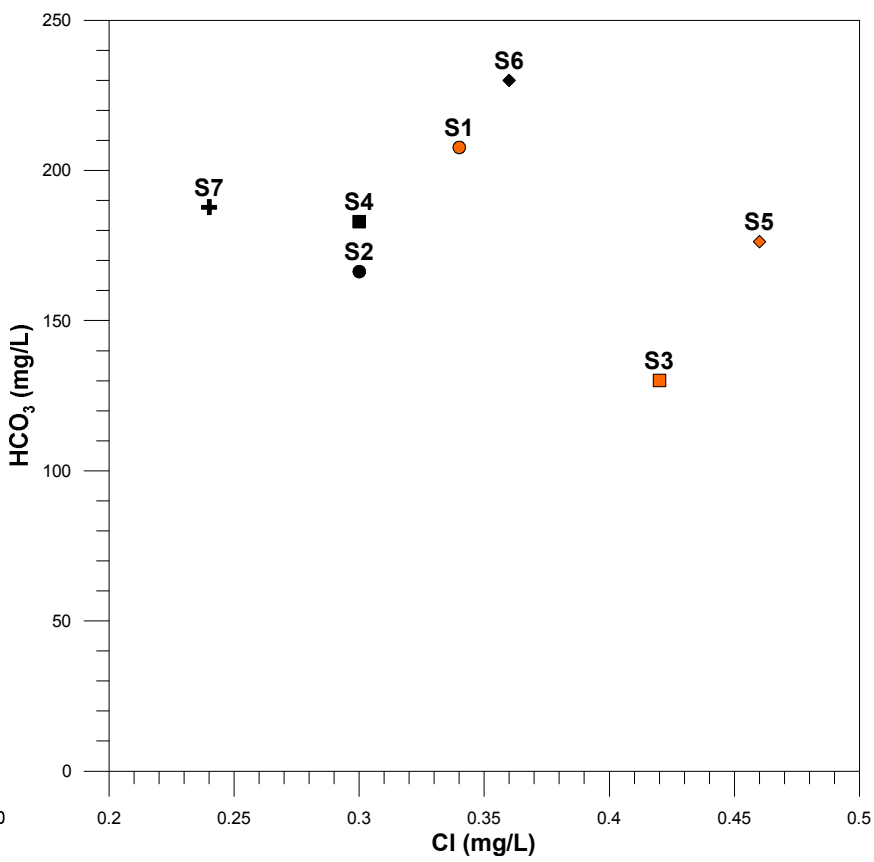

Fig. 5. Correlation plots for $\mathrm{Cl}$ and other Physico-chemical parameters (TDS and $\mathrm{HCO}_{3}$ ).
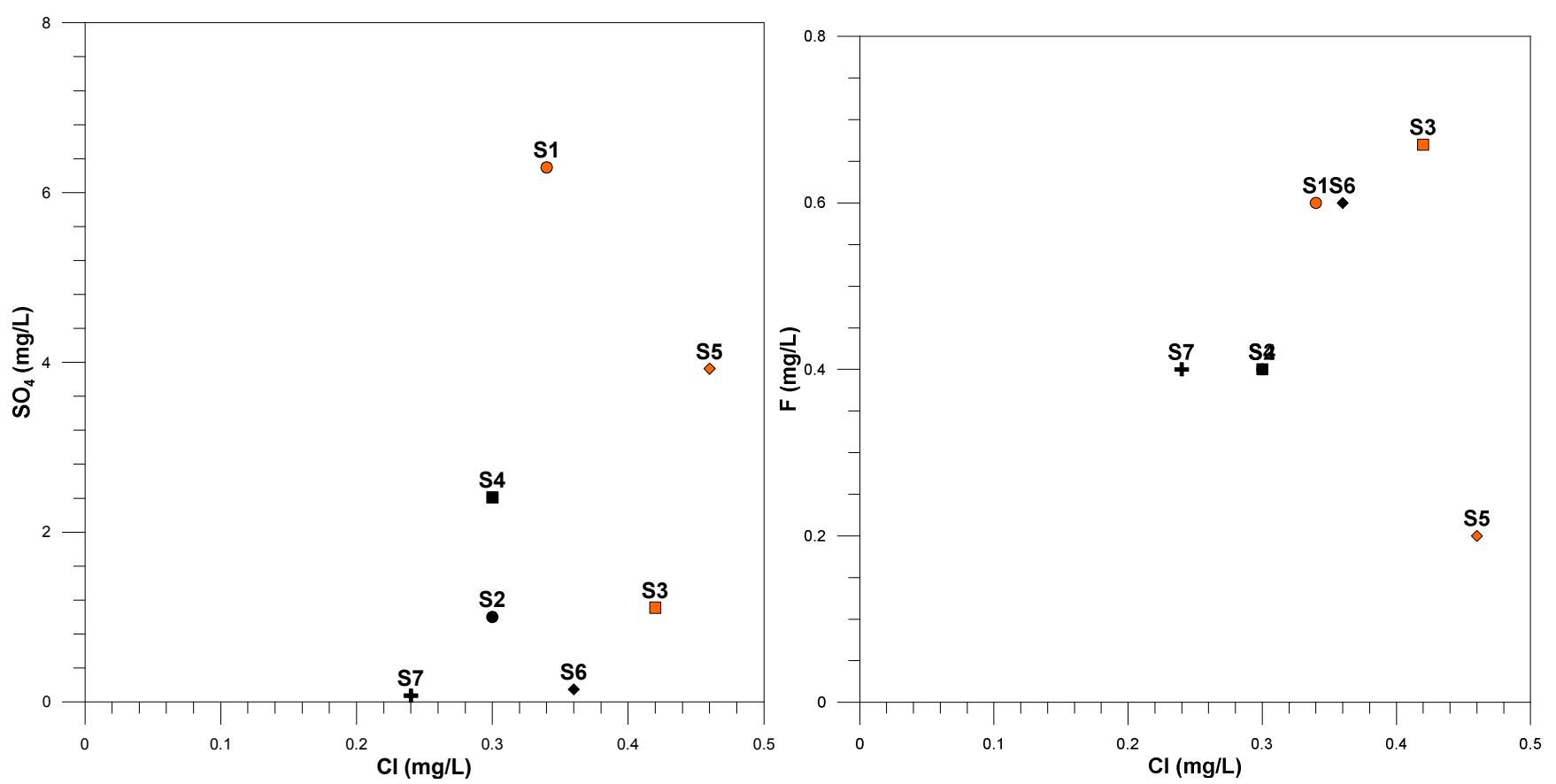

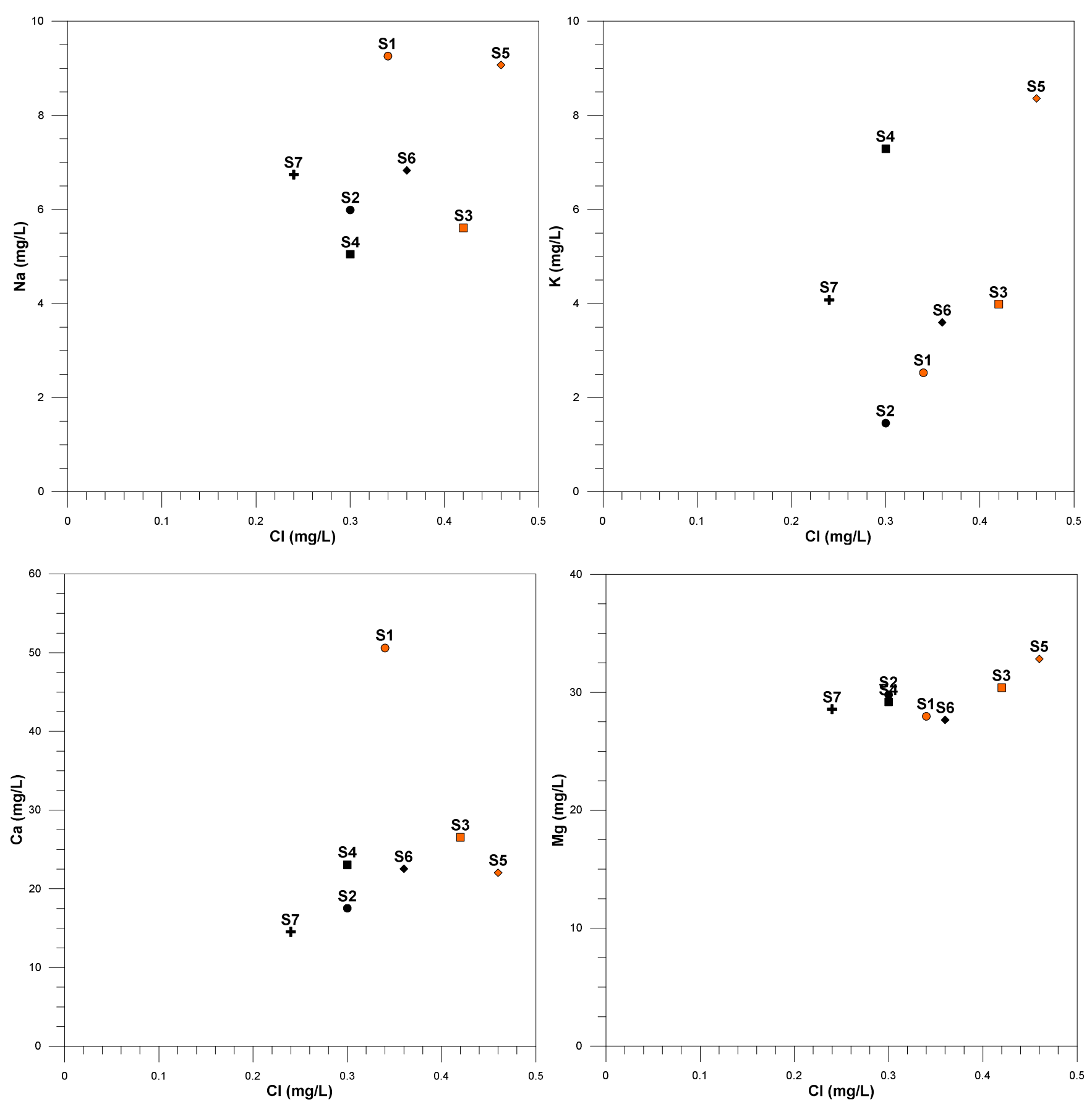

Fig. 6. Correlation plots of chloride and other species.

Remarkably, the chloride correlation with most species is significantly varied except for $\mathrm{Mg}$ which shows some regular correlation.

\subsection{Ludwig-Langelier Plots}

It has been proven in literature that the square plot of Langelier-Ludwig [5] represents the base of a compositional pyramid whose edges are the chemical concentrations, in $\mathrm{meq} / \mathrm{L}$, and whose axis express the Total Ionic Salinity (TIS, in the same unit of measurements). It is inferred that the water is of $\mathrm{Ca}-\mathrm{Mg}-\mathrm{HCO}_{3}$ through inspection of the square plot of Langelier-Ludwig (Fig. 7, left). All previous plots provide the same kind of information as they involve percentages of major dissolved constituents. The triangular cross-sections of the Langelier-Ludwig compositional pyramid allow one to obtain the information provided by TIS. Some of these triangular cross-sections are equivalent to peculiar binary correlation plots. It is inferred from the compositional pyramid that the water of hand-dug wells in Kakamega metropolis is of low salinity (TIS) as presented in Fig. 7 (left).

Generally, it is observed that alkali earth metals exceed alkali metals and weak acidic anions exceed strong acidic anions. The dominance of $\mathrm{Ca}$ and $\mathrm{Mg}$ in the groundwater samples collected suggests an inverse ion exchange process 
indicating a high topographic region of the area from where the water sample was collected. This is a strong indication that during mixing processes $\mathrm{Ca}$ from the aquifer matrix will be exchanged with $\mathrm{Na}$ from the groundwater, Fig. 7 (right).
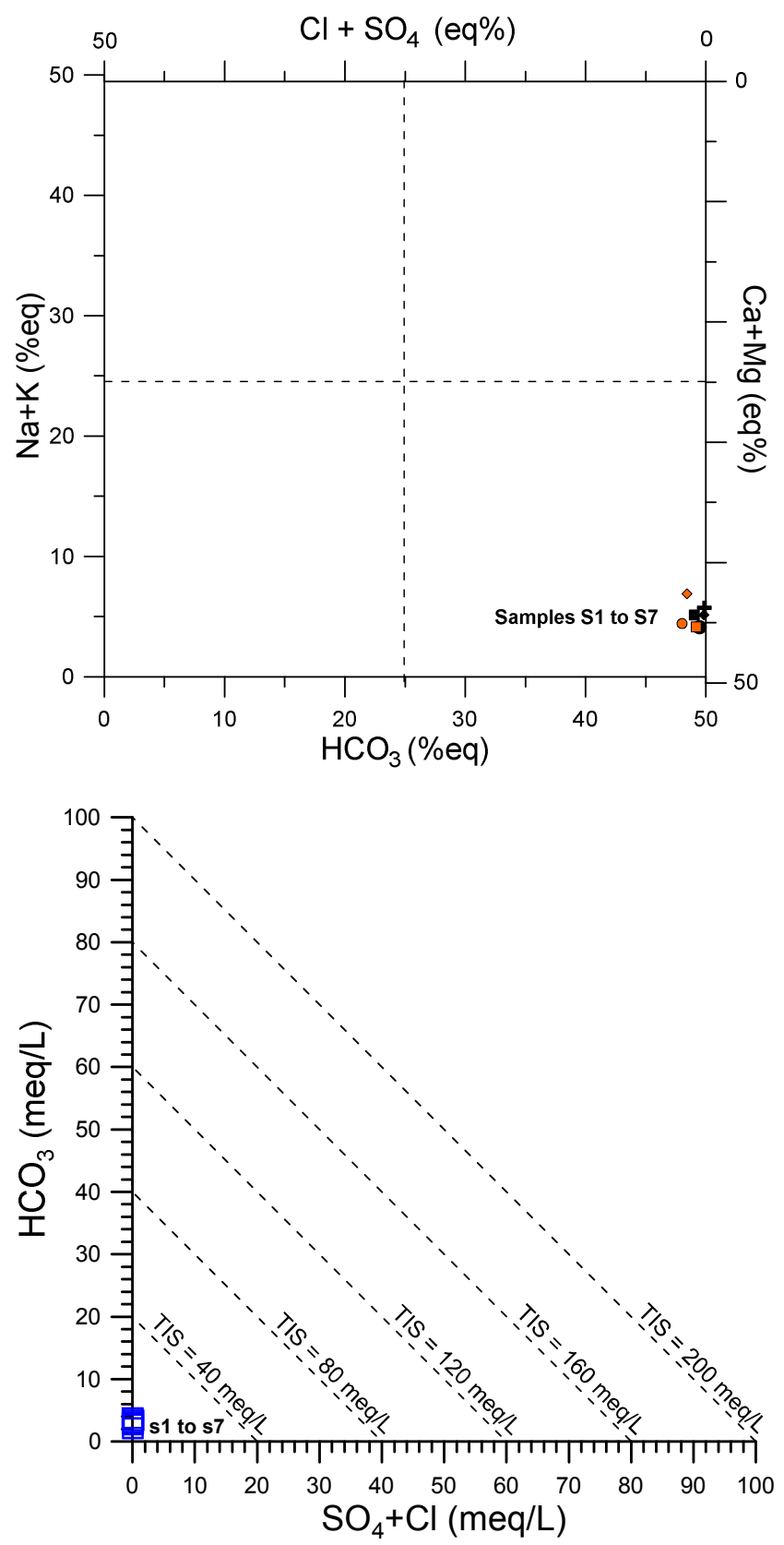

Fig. 7. Langelier-Ludwigsquare diagram (left) and correlation plot of $\mathrm{HCO}_{3}$ vs. $\mathrm{SO}_{4}+\mathrm{Cl}$ (right) for the water samples (S1 to S7) from the study area.

\subsection{Piper Diagrams}

Piper diagrams were made in such a way that the mill equivalents percentages of the major cations and anions are plotted in separate triangles [11]. These plotted points in the triangular fields are projected further into the central diamond field, which provides the overall character of the water. The water from the study area is generally $\mathrm{Ca}-\mathrm{Mg}$ $\mathrm{HCO}_{3}$ type as shown in the previous plots (Figs. 6 and 7). It is well established that each side of the triangle in the piper plot is equivalent to $100 \% \mathrm{meq} / \mathrm{L}$ and conventionally, trilinear plots are typically used to define the various ways in which the cation and the anion are combined. Historically, the expression of an individual analysis of species by two points on separate graphs was found to be inconvenient [11]. Therefore, cation and anion fields have been combined to allow the expression of an analysis as a single point in the coordinate diagram. Previously it was shown that the ratio of chloride ions to carbonates and bicarbonates is a measure of the depth of the aquifer or the water well [10]. Accordingly, it follows that the oxygeneous ions $\left(\mathrm{HCO}_{3}\right.$ and $\left.\mathrm{CO}_{3}\right)$ are relatively abundant in shallow aquifers whereas chloride ions are abundant in deep aquifers.

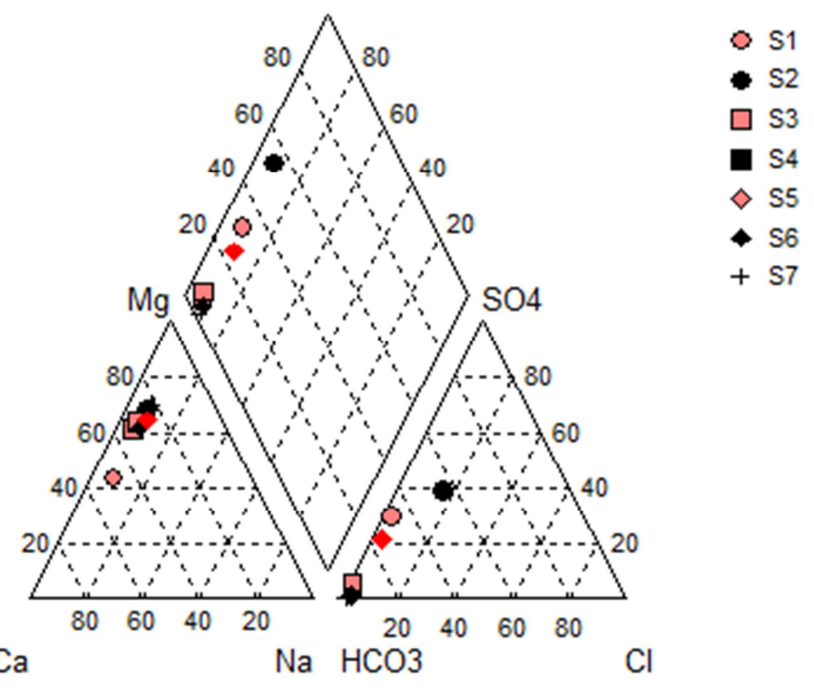

Fig. 8. Piper plot of samples S1 to S7
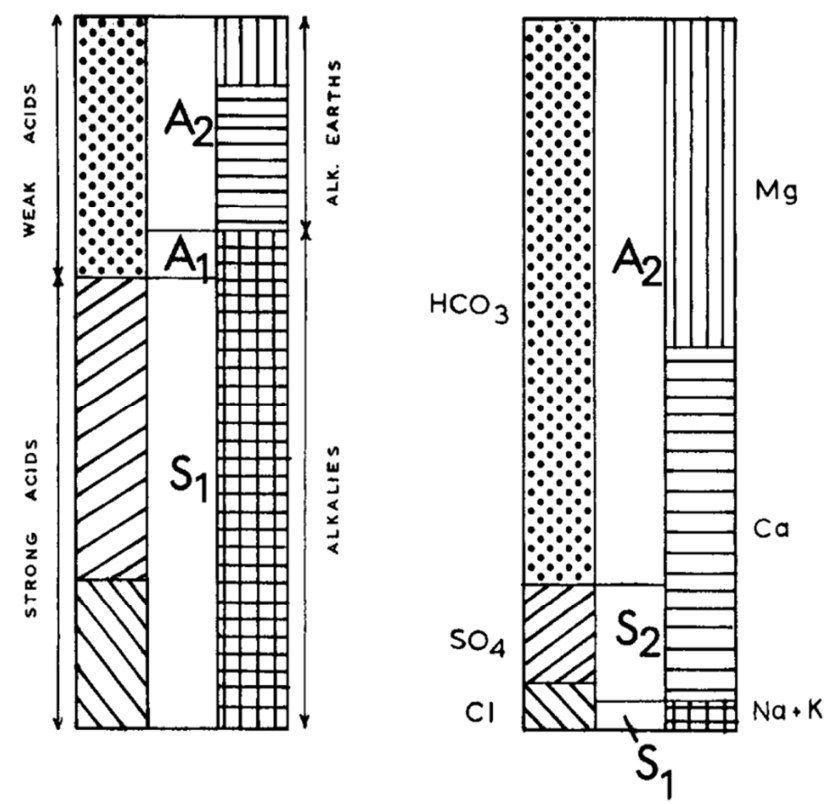

Fig. 9. Palmer-Rodgersgraph, A1, A2, S1 and S2 are Palmer's characteristics [11].

Early studies indicated that $[5,11]$ natural waters can be divided into five classes on the basis of six characteristics according to Fig. 9: (1) Primary (alkali) salinity - S1, 
formed by salts of strong acids and strong bases; (2) Secondary salinity (permanent hardness) - S2, formed by salts of strong acids and weak bases; (3) Tertiary salinity (acidity) - S3, formed by salts of strong acids and metals; (4) Primary (permanent) alkalinity - A1, formed by salts of weak acids and strong bases; (5) Secondary (temporary) alkalinity - A2, formed by salts of weak acids and weak bases and (6) Tertiary alkalinity - A3, formed by salts of weak acids and metals. Part of Palmer (1911) work is displayed in Fig. 9.

From Fig. 9, it is deduced that the waters from the study area are predominantly of the A2type (temporal alkaline). Evidently, from the discussion that the oxygen-rich ions represented by $\mathrm{HCO}_{3}$ and $\mathrm{SO}_{4}$ are relatively abundant compared to chloride implying that the water originates from shallow aquifers, and is of low salinity. The water appears to belong to the class of primary waters having very low concentration (TDS $<150 \mathrm{mg} / \mathrm{kg}$ ), whereby bicarbonates of $\mathrm{Ca}$ and $\mathrm{Mg}$ are predominant salts. The quantities present in the water are possibly determined by the local supply of each element throughout the history, origin, and migration of the water.

\subsection{Activity Coefficients and Mineral Speciation}

The activity coefficients for various species investigated were computed using AquaChem computer program and the results presented in table 2 . Whereas the activity coefficients for most species were close to unity, some species such as $\mathrm{Ca}^{2+}, \mathrm{Mg}^{2+}, \mathrm{CO}_{3}{ }^{2-}$, and $\mathrm{SO}_{4}{ }^{2-}$ were far much less than unity, ranging between 0.71 and 0.76 . This is not unusual because these species have a higher charge $( \pm 2)$ in comparison to the other species which are singly charged. This is a consequence of the Debye-Huckel limiting law which tends to fail as the ionic charge is increased [12]. The charge of \pm 2 leads to a stronger coulombic interaction and thus a stronger deviation from ideality. It is clear that AquaChem suite of program is a powerful tool in determining the activity of species in water with remarkable accuracy. The consistency of the activity coefficients of species from various sample areas shows that the data collection used in the computation was good and therefore reliable, table 3 .

Table 3. Activity coefficients.

\begin{tabular}{|c|c|c|c|c|c|c|c|c|c|c|c|}
\hline Sample & $\mathrm{HCO}_{3}^{-}$ & $\mathrm{CO}_{3}{ }^{2-}$ & $\mathrm{SO}_{4}{ }^{2-}$ & $\mathrm{Cl}^{-}$ & $\mathbf{F}^{-}$ & $\mathrm{Na}^{+}$ & $\mathbf{K}^{+}$ & $\mathrm{Ca}^{2+}$ & $\mathrm{Mg}^{2+}$ & $\mathrm{CaHCO}_{3}{ }^{+}$ & $\mathrm{MgHCO}_{3}{ }^{+}$ \\
\hline 1 & 0.92 & 0.71 & 0.71 & 0.91 & 0.92 & 0.92 & 0.91 & 0.72 & 0.73 & 0.92 & 0.92 \\
\hline 2 & 0.93 & 0.74 & 0.74 & 0.93 & 0.93 & 0.93 & 0.93 & 0.75 & 0.76 & 0.93 & 0.93 \\
\hline 3 & 0.93 & 0.74 & 0.74 & 0.92 & 0.93 & 0.93 & 0.92 & 0.75 & 0.75 & 0.93 & 0.93 \\
\hline 4 & 0.93 & 0.74 & 0.73 & 0.92 & 0.92 & 0.93 & 0.92 & 0.74 & 0.75 & 0.93 & 0.93 \\
\hline 5 & 0.92 & 0.73 & 0.73 & 0.92 & 0.92 & 0.92 & 0.92 & 0.74 & 0.75 & 0.93 & 0.92 \\
\hline 6 & 0.92 & 0.73 & 0.73 & 0.92 & 0.92 & 0.92 & 0.92 & 0.74 & 0.75 & 0.93 & 0.92 \\
\hline 7 & 0.93 & 0.75 & 0.74 & 0.93 & 0.93 & 0.93 & 0.93 & 0.75 & 0.76 & 0.93 & 0.93 \\
\hline
\end{tabular}

Legend: Sample 1- Lusui, Sample 2- Iguhu, Sample 3-Ikolomani 1, Sample 4- Ikolomani 2, Sample 5- Mupenji, Sample 6- Shilalunga, Sample 7- Shivikhwa

Table 4 gives the AquaChem output for mineral species present in Kakamega waters. Whereas it was not possible to determine the concentration of the bicarbonate, free carbonate, and carbonic acid directly from experimental procedures, AquaChem computational program was able to speciate these chemicals and give their respective concentrations accordingly. For instance, apart from the initial input of $\mathrm{HCO}_{3}{ }^{-}$estimated at $208 \mathrm{mg} / \mathrm{L}$, AquaChem program was able to estimate the concentrations of related species; carbonic acid $\left(\mathrm{H}_{2} \mathrm{CO}_{3}\right)$ and the free carbonate ion $\left(\mathrm{CO}_{3}{ }^{2-}\right.$ ) (cf. table 3). The concentration of $\mathrm{CaSO}_{4}, \mathrm{CaCO}_{3}$, $\mathrm{MgSO}_{4}, \mathrm{MgCO}_{3}, \mathrm{CaHCO}_{3}$, and $\mathrm{MgHCO}_{3}$ were also estimated using AquaChem. Thus, AquaChem computer program is a robust computational package for water analysis. It gives detailed information which can otherwise be tedious to obtain from experimental techniques.

Table 4. Mineral species (carbonates) present in Kakamega waters

\begin{tabular}{|c|c|c|c|c|c|c|c|c|c|}
\hline \multirow{2}{*}{ Sample } & \multicolumn{9}{|c|}{ Concentration (mg/L) } \\
\hline & $\mathrm{HCO}_{3}^{-}$ & $\mathrm{H}_{2} \mathrm{CO}_{3}$ & $\mathrm{CO}_{3}{ }^{2-}$ & $\mathrm{CaSO}_{4}$ & $\mathrm{MgSO}_{4}$ & $\mathrm{CaCO}_{3}$ & $\mathrm{MgCO}_{3}$ & $\mathrm{CaHCO}_{3}$ & $\mathrm{MgHCO}_{3}$ \\
\hline 1 & 208 & 18.1 & 0.31 & 0.51 & 0.73 & 0.46 & 0.24 & 3.24 & 2.77 \\
\hline 2 & 166 & 1.47 & 2.38 & 0.03 & 0.13 & 1.24 & 2.09 & 0.87 & 2.41 \\
\hline 3 & 130 & 36.00 & 0.06 & 0.05 & 0.17 & 0.06 & 0.06 & 1.23 & 2.03 \\
\hline 4 & 183 & 50.80 & 0.08 & 0.09 & 0.29 & 0.05 & 0.07 & 1.2 & 2.59 \\
\hline 5 & 176 & 17.4 & 0.24 & 0.15 & 0.63 & 0.18 & 0.24 & 1.39 & 2.92 \\
\hline 6 & 230 & 20.1 & 0.35 & 0.01 & 0.02 & 0.25 & 0.29 & 1.74 & 3.16 \\
\hline 7 & 188 & 26.3 & 0.17 & 0.01 & 0.01 & 0.07 & 0.14 & 0.81 & 2.64 \\
\hline
\end{tabular}

Legend: Sample 1- Lusui, Sample 2- Iguhu, Sample 3- Ikolomani 1, Sample 4- Ikolomani 2, Sample 5- Mupenji, Sample 6- Shilalunga, Sample 7- Shivikhwa

It is evident from table 4 that carbonic acid was the highest in sample 4 (Ikolomani 2), $50.80 \mathrm{mg} / \mathrm{L}$. A similar observation was also noted in Ikolomani 1 (sample 3), $36.00 \mathrm{mg} / \mathrm{L}$. The dominance of high levels of bicarbonates in a given regime 
suggests that the area is located within shallow aquifers. While the health effects of carbonic acid is not clearly defined in literature, there is need to investigate if there are any cases of health problems associated with high uptake of carbonic acid rich waters. With the exception of high bicarbonate $\left(\mathrm{HCO}_{3}^{-}\right)$levels in all sampled areas, most mineral species were in low concentrations. It is however, important to note that free bicarbonate, $\mathrm{HCO}_{3}{ }^{-}$, is different from bound bicarbonate such as, $\mathrm{CaHCO}_{3}$. The bicarbonate levels in the study area ranged between 130 and $230 \mathrm{mg} / \mathrm{L}$. These levels are fairly high although the bicarbonates are usually soluble in water but can easily convert to the insoluble carbonates such as $\mathrm{MgCO}_{3}$ and $\mathrm{CaCO}_{3}$.

\section{Conclusion}

This study has presented a detailed study of the mineral speciation of hand-dug well water from Kakamega Metropolis in Kakamega County, Kenya. The work predicts that the hand-dug well waterin the region belong to the class of primary waters having very low concentration of total dissolved solids (TDS $<150 \mathrm{mg} / \mathrm{kg}$ ). Piper plots suggest that the water is possibly from local supply of each element throughout history, origin, and migration of the water. Evidently, the oxygen-rich ions represented by $\mathrm{HCO}_{3}^{-}$and $\mathrm{SO}_{4}^{2-}$ were abundant compared to $\mathrm{Cl}^{-}$and $\mathrm{F}^{-}$, implying that the water originates from shallow aquifers, and is of low salinity. Moreover, we have shown that the alkali earth metals exceed alkali metals while weak acidic anions exceed strong acidic anions. The dominance of $\mathrm{Ca}$ and $\mathrm{Mg}$ in the groundwater samples collected suggests an inverse ion exchange process indicating a high topographic region where the hand-dug wells are located. During this process, Ca from the aquifer matrix is usually exchanged with $\mathrm{Na}$ from the groundwater. The Debye-Huckel limiting law incorporated in AquaChem computational platform has shown that the activity coefficients of singly charged ions approach ideality whereas doubly charged ions deviate significantly from unity because of strong coulombic interactions. This observation is remarkably consistent with experimental behavior in literature surveys.

\section{Acknowledgement}

The authors wish to thank Mr. Jeremiah Kipng'ok and Mr. Paul Kiprono of Geothermal Development Company (Kenya) for providing the necessary computational resources towards the successful completion of this task.

\section{References}

[1] West, A. G., et al., Spatial analysis of hydrogen and oxygen stable isotopes ("isoscapes") in ground water and tap water across South Africa. Journal of Geochemical Exploration, 2014. 145: p. 213-222.

[2] Stanasel, O., et al., Physical-chemistry studies on geothermal waters and scale formations. Revue Roumaine De Chimie, 2006. 51(3): p. 179-185.

[3] Kura, N. U., et al., Evaluation of Factors Influencing the Groundwater Chemistry in a Small Tropical Island of Malaysia. Int. J. Environ. Res. Public Health, 2013. 10: p. 1861-1881.

[4] Services, S. W., A Professional Application for Water Quality Data Analysis, Plotting, Reporting, and Modeling, in AquaChem, 2014: Reykjavik, Iceland. p. 1-400.

[5] Karmegam, U., et al., A study on the mixing proportion in groud water samples by using piper diagram and phreeqc model. Chinese Journal of geochemistry, 2011. 30: p. 490.

[6] Akabzaa, T. M., Impact of mining activities on water in the vicinity of the Obuasi Mine. 2005. 79: p. 377-379.

[7] Zhong-he, P. and H. Ármannsson, eds. Analytical Procedures and Quality Assurance for Geothermal Water Chemistry. Journal of Analytical and Applied Pyrolysis. 2005, United Nations University Geothermal Training Programme: Reykjavik, Iceland. p. 1-229.

[8] Freedman, A. J. E., et al., Hydrothermal Minerals Record Co(2) Partial Pressures in the Reykjanes Geothermal System, Iceland. American Journal of Science, 2009. 309(9): p. 788833.

[9] Arnórsson, S., The quartz and $\mathrm{Na} / \mathrm{K}$ geothermomters. II. Results and application for monitoring studies. Proceedings of the world geothermal congress 2000, Kyushu-Tohoku, Japan, 2000: p. 935-940.

[10] Giggenbach, W. F., Geothermal solute equilibria. Derivation of Na-K-Mg-Ca geoindicators. Geochim. Cosmochim. Acta, 1988. 52: p. 2749-2765.

[11] Chadha, D. K., A Proposed New Diagaram for GeoChemical Classification of Natural Waters and Interpretation of Chemical Data Hydrogeology Journal 1999. 7(5): p. 431-439.

[12] McGarrie, D. A. and D. J. Simon, Physical Chemistry: A Molecular Approach. University Science Books, ed. A. McGuire. Vol. 1. 1997, Sausalito, CA, USA: Edwards Brothers, Inc. p. 1-1360. 